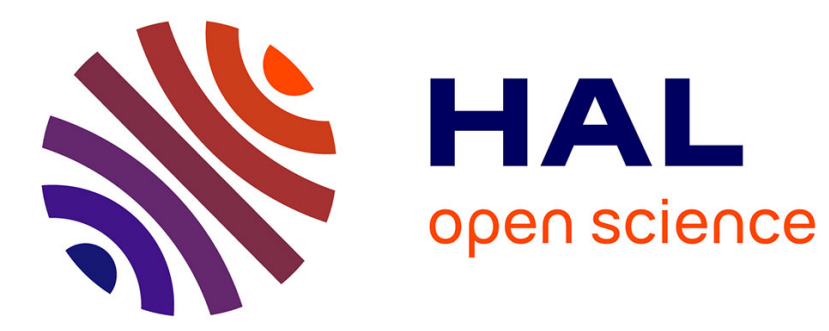

\title{
Diode pumping of Nd:ASL and its frequency doubling for blue emission around $450 \mathrm{~nm}$
}

David Pabœuf, Gaëlle Lucas-Leclin, Patrick Georges, Bernd Sumpf, Götz Erbert, Cyrille Varona, Pascal Loiseau, Gérard Aka, Bernard Ferrand

\section{- To cite this version:}

David Pabœuf, Gaëlle Lucas-Leclin, Patrick Georges, Bernd Sumpf, Götz Erbert, et al.. Diode pumping of Nd:ASL and its frequency doubling for blue emission around $450 \mathrm{~nm}$. Photonics West - LASE 2008, Jan 2008, San Jose, United States. pp.87112, 10.1117/12.769125 . hal-00531355

\section{HAL Id: hal-00531355 \\ https://hal-iogs.archives-ouvertes.fr/hal-00531355}

Submitted on 2 Nov 2010

HAL is a multi-disciplinary open access archive for the deposit and dissemination of scientific research documents, whether they are published or not. The documents may come from teaching and research institutions in France or abroad, or from public or private research centers.
L'archive ouverte pluridisciplinaire HAL, est destinée au dépôt et à la diffusion de documents scientifiques de niveau recherche, publiés ou non, émanant des établissements d'enseignement et de recherche français ou étrangers, des laboratoires publics ou privés. 


\title{
Diode pumping of Nd:ASL and its frequency doubling for blue emission around $450 \mathrm{~nm}$
}

\author{
David Paboeuf*a ${ }^{*}$, Gaëlle Lucas-Leclin ${ }^{\mathrm{a}}$, Patrick Georges ${ }^{\mathrm{a}}$, Bernd Sumpf ${ }^{\mathrm{b}}$, Götz Erbert ${ }^{\mathrm{b}}$, Cyrille \\ Varona $^{\mathrm{c}}$, Pascal Loiseau ${ }^{\mathrm{c}}$, Gérard Aka ${ }^{\mathrm{c}}$, Bernard Ferrand ${ }^{\mathrm{d}}$ \\ a Laboratoire Charles Fabry de L'Institut d'Optique, CNRS, Univ Paris-Sud, Campus Polytechnique, \\ RD128, 91127 Palaiseau Cedex, France; \\ ${ }^{\mathrm{b}}$ Ferdinand Braun Institut für Höchstfrequenztechnick, Albert-Einstein-Strasse 11, 12489 \\ Berlin, Germany \\ ${ }^{c}$ Laboratoire de Chimie de la Matière Condensée de Paris, CNRS, ENSCP, 11 rue P. et M. Curie, \\ 75231 Paris, France \\ ${ }^{\mathrm{d}}$ Laboratoire de Cristallogenèse Appliquée, CEA - LETI 17 Rue des martyrs, 38054 Grenoble,
} France

\begin{abstract}

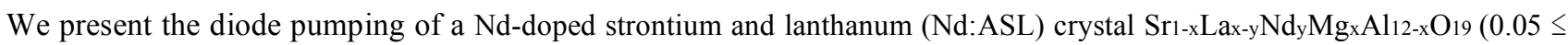
$\mathrm{x} \leq 0.5 ; \mathrm{y}=0.05$ ) for second harmonic generation around $450 \mathrm{~nm}$. In order to fulfill the pumping requirements of this crystal, we have developed a high-brightness pump source based on a tapered amplifier in an extended cavity with a volume Bragg grating for wavelength stabilization. A pump brightness of $110 \mathrm{MW} . \mathrm{cm}^{-2} \mathrm{sr}^{-1}$ has been obtained with a linewidth lower than $80 \mathrm{pm}$ at $798 \mathrm{~nm}$. This laser source has been used to pump a Nd:ASL crystal to obtain $300 \mathrm{~mW}$ at $906 \mathrm{~nm}$ and $53 \mathrm{~mW}$ at $453 \mathrm{~nm}$ by intracavity doubling with a LBO crystal.
\end{abstract}

Keywords: diode pumped solid-state lasers, rare earth, second harmonic generation, neodymium, volume holographic grating,

\section{INTRODUCTION}

Diode-pumped solid-state lasers operating in the blue spectral range have a large number of applications ranging from high-density optical data storage to phototherapy and medical diagnostic. One way to design such a laser is to perform non linear conversion of a near infrared laser line. The neodymium 4F3/2 - 4I9/2 laser transition is one of the most used for the initial infrared source since it allows emission around $900 \mathrm{~nm}$. For instance, efficient frequency doubling has been demonstrated with Nd:YAG (473 nm)[1], Nd:YVO4 (456 nm) [2] and Nd:GdVO4 (456 nm) [3]. In order to reach deeper blue wavelengths, two ways are possible. The first one is to design a cavity emitting on a deeper Stark sub-level with a conventional Nd-doped crystal; quasi-3-level laser emission at $899 \mathrm{~nm}$ in Nd:YAG has indeed been recently demonstrated [4]. Another solution consists in developing new neodymium-doped laser materials.

Among them, Nd-doped strontium and lanthanum (Nd:ASL) crystal Sr1-xLax-yNdyMgxA112-x O19 is very promising since its quasi-three-level transition is located at $900 \mathrm{~nm}$, one of the lowest existing in Nd-doped crystals[5]. Unfortunately, the absorption transitions of Nd:ASL are narrow-band $(<3 \mathrm{~nm})$ and located at $792 \mathrm{~nm}$ and $798 \mathrm{~nm}$ (see Fig. 7) where commercial high power laser diodes are difficult to find. Moreover the quasi-3-level operation of the laser implies that the lower level of the laser transition is thermally populated. A bright enough pump source is then required to exceed the transparency intensity $(3 \mathrm{~kW} . \mathrm{cm}-2)$ and get a positive gain. Under Ti:Sa pumping at $792 \mathrm{~nm}, 1.67 \mathrm{~W}$ of infrared laser at $900 \mathrm{~nm}$ have been demonstrated in [6]. Furthermore, intracavity doubling with a BiBO crystal produced $320 \mathrm{~mW}$ of blue laser power at $450 \mathrm{~nm}$. In regard with these efficient results, the demonstration of the diode pumping of this crystal would be an interesting improvement in terms of compacity and wall-plug efficiency. With this purpose, we have developed our own high-brightness wavelength-stabilized pumping source at $798 \mathrm{~nm}$ based on a tapered amplifier in extended cavity with a volume Bragg grating.

In this paper, we first present the design and characteristics of the pumping source and then the use of this source to perform infrared emission and intracavity second harmonic generation in Nd:ASL.

*david.paboeuf@institutoptique.fr 


\section{DESIGN AND CHARACTERIZATION OF THE PUMPING SOURCE}

\subsection{Tapered laser diodes}

Tapered laser diodes are one of the most promising designs proposed for high brightness emission in the 1-W power range. It consists of a single-mode ridge acting as a spatial filter and a large tapered amplifying section. Several achievements have been described in the literature, demonstrating high output powers in a nearly diffraction-limited beam [7-9]. A super-large optical-cavity structure (SLOC) for emission around $800 \mathrm{~nm}$ has been designed as in [9]. The active region consists of a single GaAsP quantum well embedded in a 3- $\mu$ m thick $\mathrm{Al}_{0.45} \mathrm{Ga}_{0.55} \mathrm{As}_{\text {s }}$ waveguide. The vertical far-field angle was as low as $18.3^{\circ}$ (FWHM) and $95 \%$ of the power was included in an angle of $32.5^{\circ}$. The length $\mathrm{L}_{\mathrm{r}}$ of the index-guided straight ridge section was $2 \mathrm{~mm}$, and the angle of the gain-guided tapered section was $\varphi=4^{\circ}$. The full amplifier length was $4 \mathrm{~mm}$. The front facet had a reflectivity $R_{f}$ of $0.5 \%$ whereas the rear facet reflectivity $R_{r}$ was $<5 \times 10^{-}$ ${ }^{3}$. The devices were mounted p-side (epi-side) down on $\mathrm{CuW}$ submounts and, thereafter, on C-mounts. No laser emission was observed from these devices, but amplified spontaneous emission in a $\sim 25 \mathrm{~nm}$ spectral range. With the same design $\left(\mathrm{L}_{\mathrm{r}}=1 \mathrm{~mm}, \varphi=4^{\circ}\right)$ but coatings $\mathrm{R}_{\mathrm{f}} \cong 0.1 \%$ on the front facet and $\mathrm{Rr} \cong 94 \%$ on the rear facet, a tapered laser diode has demonstrated an output power of about $4 \mathrm{~W}$ and a beam quality parameter M2 $<1.9$ [9].

\subsection{Volume Bragg gratings}

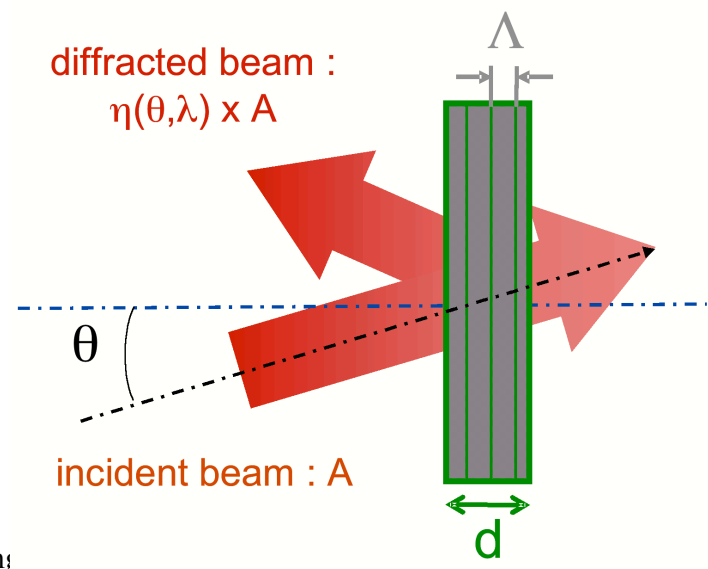

Fig.1 Schematic of a reflectin!

Volume Bragg gratings have appeared to become essential optical components in the recent years, with a high spectral selectivity, low losses and reflectivity from a few $\%$ to $100 \%$. Is consists of a photo-refractive glass in which an index modulation has been recorded under UV illumination. Bragg gratings act as spectral and angular filter according to the Bragg condition: $\cos (\theta)=\lambda /\left(2 \mathrm{n}_{0} \Lambda\right)$. For a reflecting volume Bragg grating (VBG) with unslanted index fringes characterized by a thickness $\mathrm{d}$, a grating period $\Lambda$, an average index $\mathrm{n}_{0}$ and an index modulation $\Delta \mathrm{n}$ (see Figure 1), the diffraction efficiency $\eta(\theta, \lambda)$ using the same notations as in [10], is given by :

$$
\left.\eta=\left(1+\frac{1-\frac{\xi^{2}}{v^{2}}}{s h^{2}\left(\sqrt{v^{2}-\xi^{2}}\right.}\right)\right)^{-1}
$$

$\xi$ characterizes the mismatch to the Bragg condition. The computation of the diffraction efficiency in respect with the incident angle of the beam and wavelength for a $0.7-\mathrm{mm}$-thick VBG designed to reflect $20 \%$ at $798 \mathrm{~nm}$ is presented on Figure 2. From these calculations, the spectral selectivity of the grating is evaluated to $300 \mathrm{pm}$ (full-width at $1 / \mathrm{e}^{2}$ ) and its angular selectivity to $2^{\circ}$ ( full-width at $1 / \mathrm{e}^{2}$ ). 


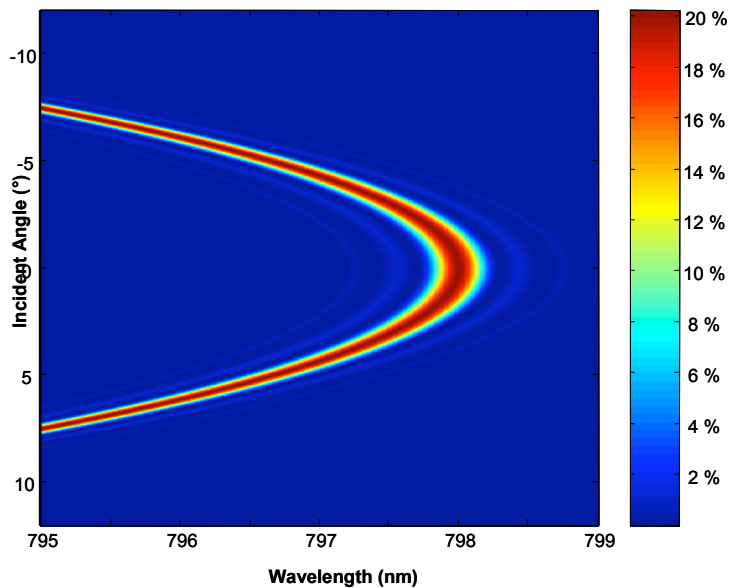

Fig.2 Computation of the evolution of the diffraction efficiency of a VBG designed at $798 \mathrm{~nm}$ $\left(\mathrm{d}=0.7 \mathrm{~mm}, \Delta \mathrm{n}=1.746 \times 10^{-4}, \lambda_{\mathrm{B}}=798 \mathrm{~nm}\right)$

\subsection{Tapered amplifier in extended cavity}

The set-up of our tapered amplifier in extended cavity is presented on Figure 3. We used a VBG centered at $798 \mathrm{~nm}$, with a reflectivity of $20 \%$ and a spectral bandwidth of $200 \mathrm{pm}$, as the back mirror of the extended cavity. The Bragg grating acts as a spectrally selective end-mirror of the external cavity, and the useful output power is emitted from the tapered side. The emission from the ridge side of the tapered amplifier is focused into the Bragg grating with a high-NA aspheric lens pair (Thorlabs C230220P: $\mathrm{f}_{\text {coll }}=4.5 \mathrm{~mm} 0.55 \mathrm{NA} / \mathrm{f}^{\prime}{ }_{\text {foc }}=15.4 \mathrm{~mm} 0.16 \mathrm{NA}$ ) for diffraction-limited imaging.

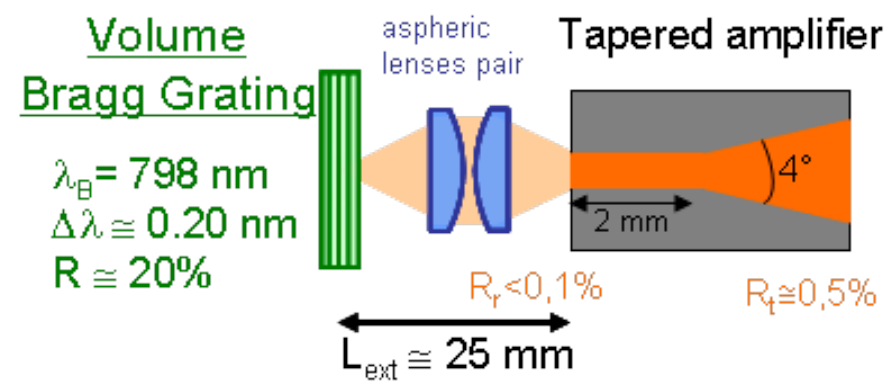

Fig.3 Set-up of the tapered amplifier in extended cavity

The major feature of our external cavity set-up is the focusing of the beam inside the Bragg grating, while it has been designed for a collimated beam. The resulting "cat's eye" effect improves the mechanical stability of the laser cavity as in self-aligned Littman cavities [11] or interference-filter stabilized external cavities [12]. Here the Bragg grating allows us to take benefit from this helpful effect in both transverse directions. Indeed, we evaluate the precision required on the lens pair position in $\mathrm{X}$ and $\mathrm{Y}$ directions to about $\pm 45 \mu \mathrm{m}$ for a reduction of the power of $80 \%$ with our focused-beam configuration. In the longitudinal axis the misalignments tolerance is $\Delta \mathrm{Z}= \pm 12 \mu \mathrm{m}$. These values are much larger than the usual tolerances in collimated-beam configurations.

Whatever the operating current or the temperature, the laser emission was locked on the Bragg wavelength with a very low wavelength shift that remained included into the VBG spectral bandwidth (see Fig. 4). We measured a side-mode suppression ratio higher than $40 \mathrm{~dB}$ and a FWHM-linewidth lower than $80 \mathrm{pm}$ (OSA-limited). The threshold of the extended cavity laser diode was as low as $1 \mathrm{~A}$ and the slope efficiency reached $0.9 \mathrm{~W} . \mathrm{A}^{-1}$. A maximum output power of $2.5 \mathrm{~W}$ has been measured for an operating current of $3.5 \mathrm{~A}$ (see Fig. 5). The beam quality parameter $\left(\mathrm{M}^{2}\right)$ was as good as 1.2 in both directions for an operating current of $2.5 \mathrm{~A}$ (see Fig. 6). At higher operating currents we observed a degradation of the beam quality and measured a $\mathrm{M}^{2}$ around 3 in the slow axis direction. This result in a pump brightness 
of $110 \mathrm{MW} \cdot \mathrm{cm}^{-2} \mathrm{sr}^{-1}$. All these features make this pumping source fully suitable to the optical pumping of an Nd:ASL crystal and may result in a major improvement in terms of compactness and wall-plug efficiency compared to Ti:Sa pumping.

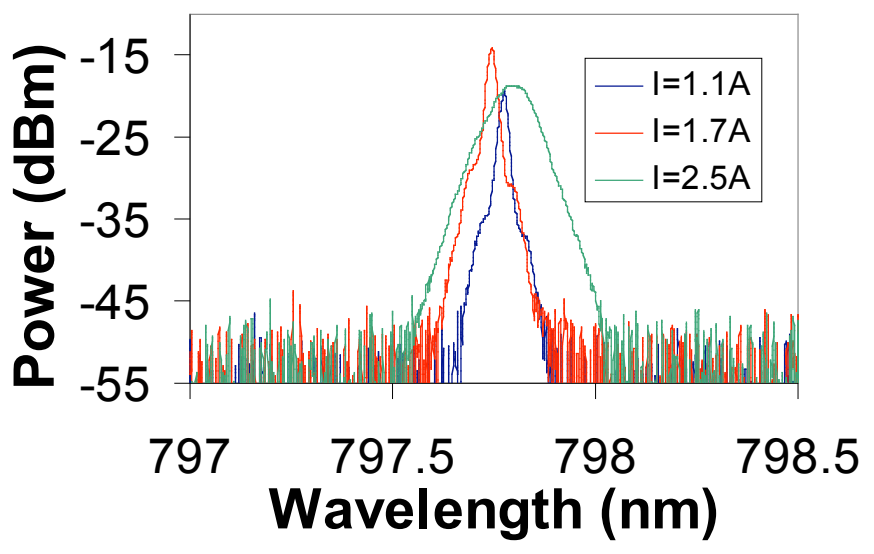

Fig.4 Spectrum of the pumping source for various operating current

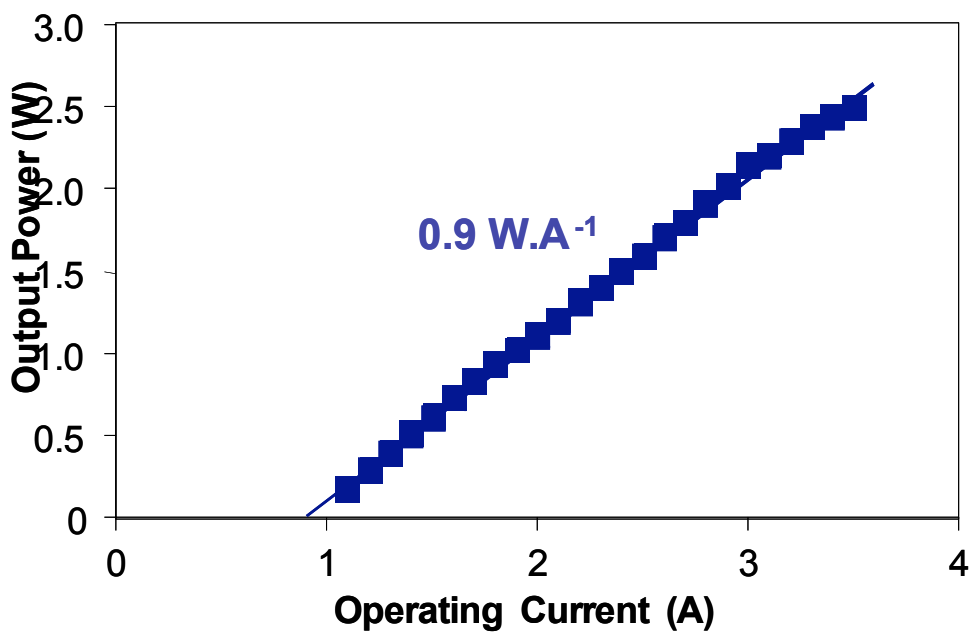

Fig.5 Power characteristic of the pumping source 


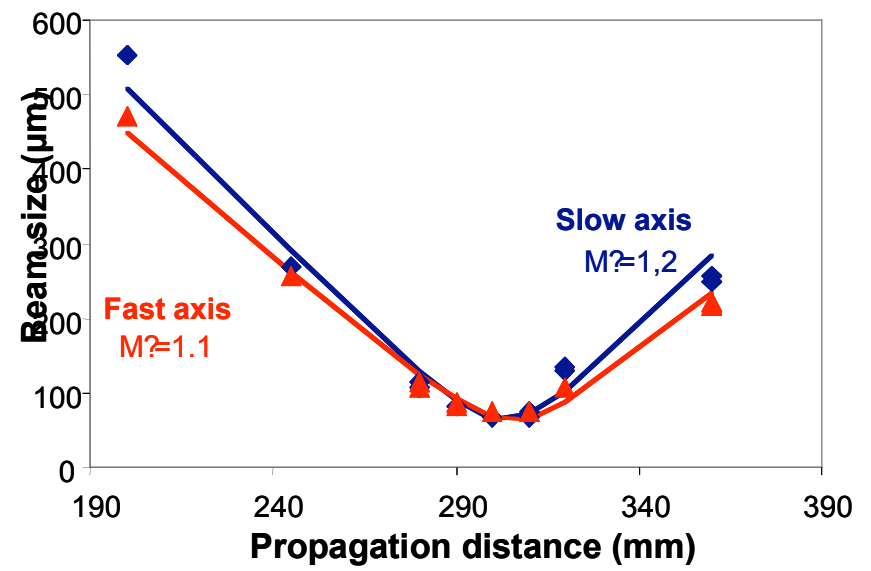

Fig.6 Beam quality factor measurement $(\mathrm{I}=2 \mathrm{~A}, \mathrm{P}=1.1 \mathrm{~W})$

\section{INFRARED OPERATION}

With quasi-three level lasers, reabsorption at the oscillating wavelength is the main challenge to face. The available pump power being limited, the pump beam has to be strongly focused inside the crystal to reach a high intensity at the waist position. This results in a very diverging beam with reduced pump intensity at the crystal output. Reabsorption may then occur and limit the laser efficiency. Thus, simulations have been carried out to evaluate the gain inside the crystal and determine the theoretical adequate parameters. The small signal gain integrated on the transverse section of the crystal can be written as [13]:

$$
g_{0}(z)=\int_{0}^{r_{c}} N \frac{\sigma_{e L} \sigma_{a P} I_{p}(r, z) h v_{p}-\sigma_{a L} / \tau}{\sigma_{a P} I_{p}(r, z) h v_{p}-1 / \tau} \times A(r, z) d r
$$

where $\mathrm{N}$ is the density of neodymium ions in the crystal, $\sigma_{\mathrm{a}}$ the absorption cross section at the pump wavelength, $\tau$ the fluorescence lifetime. $I_{p}(r, z)$ is the pump intensity taking into account the Gaussian propagation of the pump beam. In the model, we assume there is no change in the spatial profile of the pump due to absorption. $\sigma_{\mathrm{eL}}$ and $\sigma_{\mathrm{aL}}$ are, respectively, the emission and absorption cross sections at the laser wavelength. A(r,z) stands for the Gaussian profile of the laser mode. The double pass gain inside the crystal is given by:

$$
G=\int_{0}^{L} e^{2 g_{0}(z)} d z
$$

The spectroscopic data used are listed in Table 1 . The crystal is assumed to be cylindrical with a radius $r_{c}$ much larger than the beam size. Fig. 8 (left) shows the evolution of $\mathrm{g}_{0}$ along the crystal for different pump waist radii and an incident pump power of $300 \mathrm{~mW}$ close to the experimental threshold values. The laser and pump waists are supposed to be equal and located at the input of the crystal. With a small pump waist $(6 \mu \mathrm{m})$, the gain is very high at the beginning of the crystal. The beam being very divergent, the gain decreases very quickly and reabsorption occurs beyond a transparency length of $\sim 1.4 \mathrm{~mm}$. In contrast, with a too large pump waist, even at the beginning of the crystal, the gain is very low because of the strongly reduced incident pump intensity. We have also computed the evolution of the double pass gain $\mathrm{G}$ for different pump waist radii and crystal lengths on Figure 8 (right). From these simulations, we expect the laser gain will be the highest with a waist radius of $10 \mu \mathrm{m}$ and a crystal length of 2-3 $\mathrm{mm}$.

Table 1 Spectroscopic data of Nd:ASL

\begin{tabular}{cccc}
\hline$\sigma_{\mathrm{eL}} @ \mathbf{9 0 0} \mathbf{n m}$ & $\boldsymbol{\sigma}_{\mathrm{aL}} @ \mathbf{9 0 0} \mathbf{n m}$ & $\boldsymbol{\sigma}_{\mathrm{aP}}$ & $\boldsymbol{\tau}$ \\
\hline $2.310^{-20} \mathrm{~cm}^{2}$ & $410^{-21} \mathrm{~cm}^{2}$ & $2.810^{-20} \mathrm{~cm}^{2}$ & $380 \mu \mathrm{s}$ \\
\hline $\boldsymbol{\sigma}_{\mathrm{eL}} @ \mathbf{9 0 6} \mathbf{~ n m}$ & $\boldsymbol{\sigma}_{\mathrm{aL}} @ \mathbf{9 0 6} \mathbf{~ n m}$ & $\mathbf{N}(\mathbf{5 \%}$ at.) & \\
\hline
\end{tabular}




$710^{-21} \mathrm{~cm}^{2} \quad 510^{-22} \mathrm{~cm}^{2} \quad 1.710^{20} \mathrm{~cm}^{-3}$
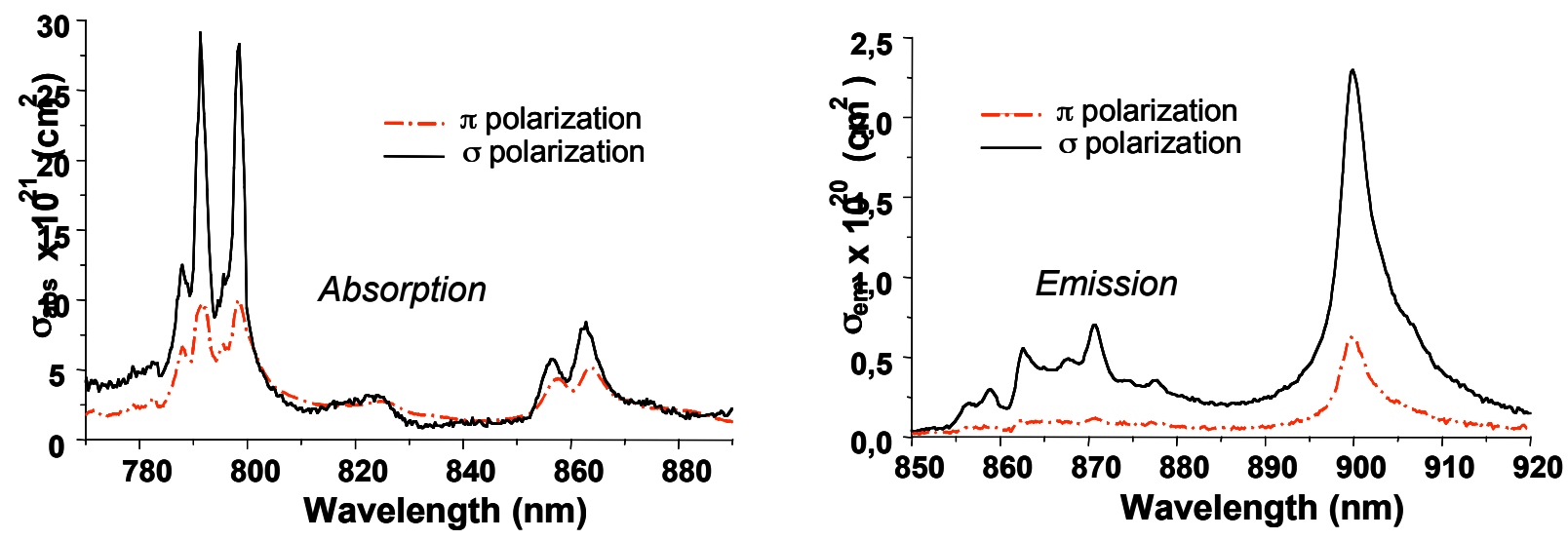

Fig.7 Absorption and emission spectrum of a Nd:ASL crystal
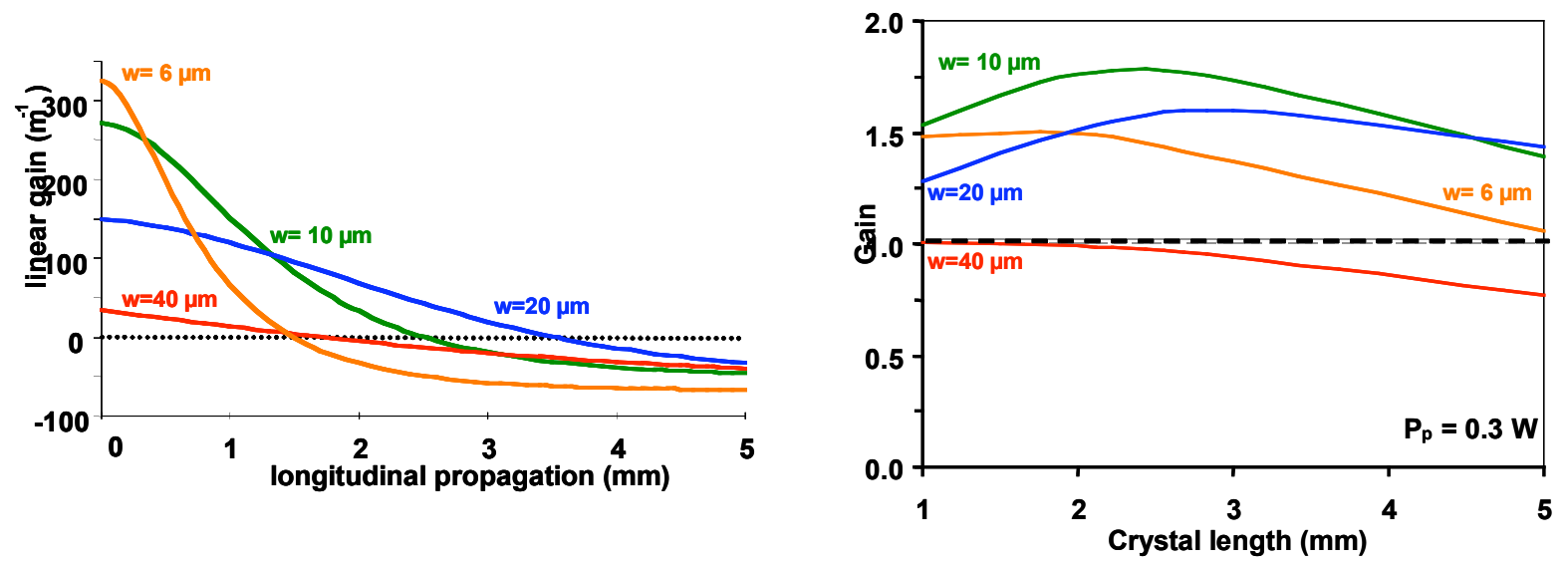

Fig. 8 left : Evolution of the small-signal gain with the crystal length for different pump waists radii - Pump power = $300 \mathrm{~mW}$. right : Evolution of the integrated gain with the crystal length for various pump waist radii at an incident pump power of $300 \mathrm{~mW}$.

We first investigated $\mathrm{cw}$ laser emission at $900 \mathrm{~nm}$. The experimental setup is presented in Fig. 9. The strong astigmatism of the tapered amplifier was corrected by use of a cylindrical lens with a focal length of $300 \mathrm{~mm}$ to both correct and circularize the pump beam. An optical isolator (isolation factor $>20 \mathrm{~dB}$ ) has been placed at the output of the tapered amplifier to avoid parasitic back-reflections. The pump waist radius could be varied by changing the focal length of the focusing lens. We used a 5\%-doped Nd:ASL $\left(\mathrm{N} \sim 1.710^{20} \mathrm{~cm}^{-3}\right)$ crystal grown by the Czochralski pulling technique. In order to minimize thermal population of the ground laser level, the copper mount of the Nd:ASL crystal was maintained at $14^{\circ} \mathrm{C}$ with a water cooling device. The resonator was a simple plane-concave cavity with the plane mirror $(\mathrm{HR} 900 \mathrm{~nm}$ - HT $800 \mathrm{~nm}$ ) deposited on the input face of the crystal and a 100-mm-curvature concave output mirror transmitting 5\% at $900 \mathrm{~nm}$ and highly transmitting at the pump wavelength. Both were anti-reflection coated at $1050 \mathrm{~nm}$ to prevent laser emission from the intense ${ }^{4} \mathrm{~F}_{3 / 2}-{ }^{4} \mathrm{I}_{11 / 2}$ 4-level-transition. In order to maximize the gain and avoid reabsorption the overlap between the laser beam and the pump beam has been optimized by setting up the cavity length and the focus position of the pump beam. 


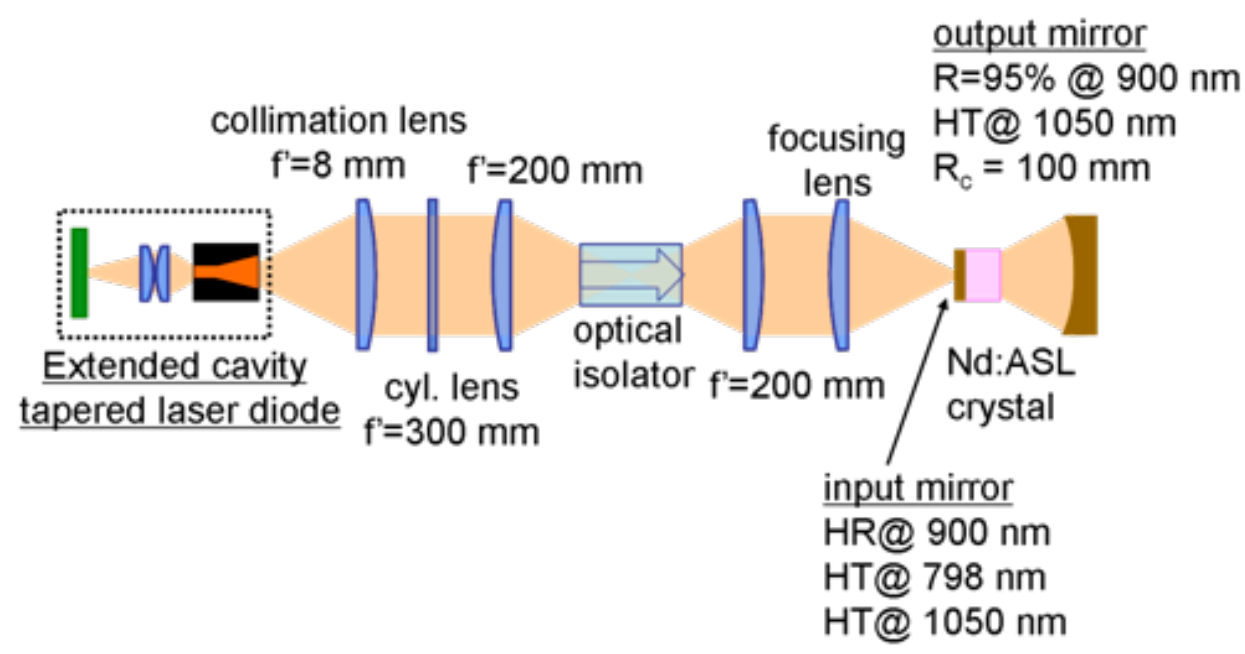

Fig. 9 Experimental setup for cw $900 \mathrm{~nm}$ emission of Nd:ASL

As expected, the maximum output power has been obtained with a 3-mm long crystal and a pump waist radius of $10 \mu \mathrm{m}$ corresponding to a $\mathrm{f}=50 \mathrm{~mm}$-focusing lens. We obtained $156 \mathrm{~mW}$ for $1.1 \mathrm{~W}$ incident pump power. The threshold was $200 \mathrm{~mW}$. The optical-to-optical slope efficiency was $17 \%$.

In order to evaluate the possibility of intracavity frequency doubling of the infrared beam we have tested a laser cavity with an output coupler highly reflecting at both the laser wavelength $(\mathrm{R}=99.85 \%)$ and a pump waist increased to $20 \mu \mathrm{m}$. The output mirror was also high reflective for the pump $(\mathrm{R}=99.95 \%)$, allowing thus pump recycling for increased pump absorption. In these conditions, instead of the $900 \mathrm{~nm}$ line obtained previously, we observed a laser emission at $906 \mathrm{~nm}$ corresponding to the transition from the ${ }^{4} \mathrm{~F}_{3 / 2}$ level to the highest Stark sub-level of the ${ }^{4} \mathrm{I}_{9 / 2}$ level. The output power at 906 $\mathrm{nm}$ through the low-transmission concave mirror reached $300 \mathrm{~mW}$ at the incident pump power of $1.5 \mathrm{~W}$ corresponding to an intracavity power of $200 \mathrm{~W}$. This relatively high value is a consequence of the pump recycling which increases the inversion population in the crystal.

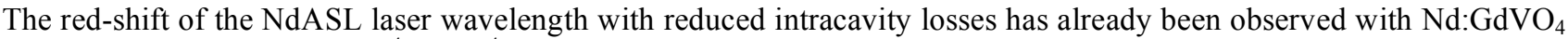
laser operating on the same ${ }^{4} \mathrm{~F}_{3 / 2}-{ }^{4} \mathrm{I}_{9 / 2}$ transition [14] and with Er:Yb:glass [15]. It is a consequence of the lower absorption cross section at $906 \mathrm{~nm}$ as compared to $900 \mathrm{~nm}$ (see Table 1). This appears clearly on Fig. 10 which computes the double-pass gain of the two transitions in respect with the pump power taking into account the different experimental set-up. Indeed the threshold at $906 \mathrm{~nm}$ is lower than the one at $900 \mathrm{~nm}$ in the HR cavity $(\mathrm{G}=1.01)$. On the contrary with a higher output coupler $(\mathrm{T}=5 \%)$, the lowest threshold is for the $900-\mathrm{nm}$ emission.

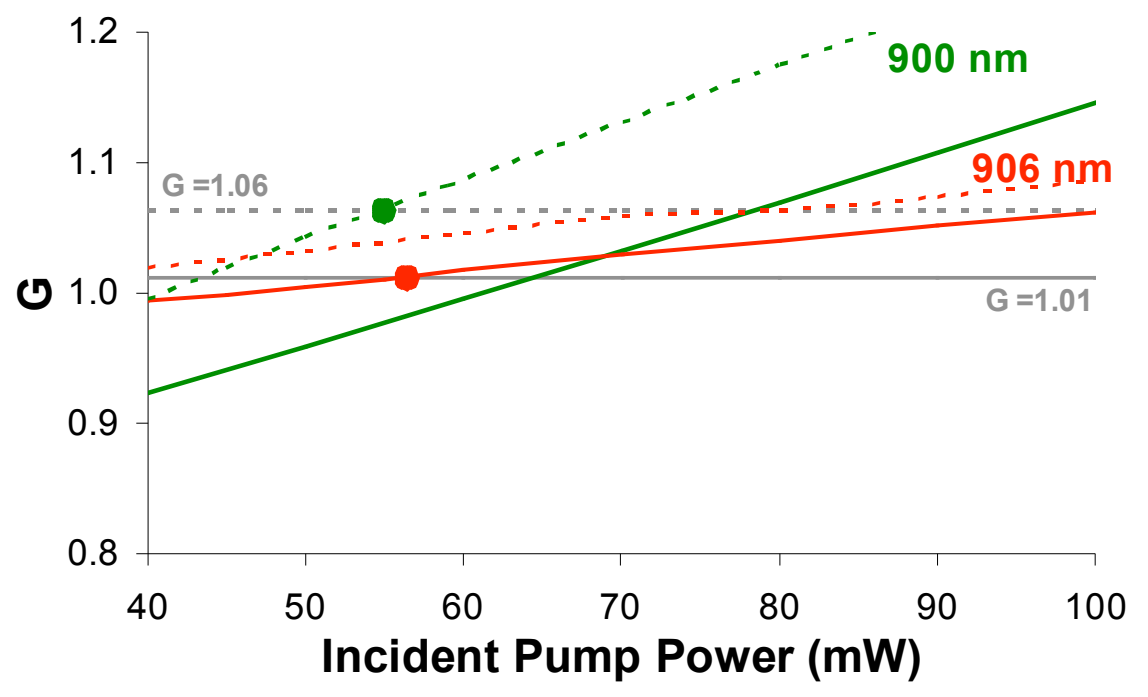


Fig. 10 Threshold gain vs incident pump power for the 2 set-up investigated : solid ( $w=20 \mu \mathrm{m}, \mathrm{R}=99.85 \%$, pump recycling), dash ( $\mathrm{w}=10 \mu \mathrm{m}, \mathrm{R}=95 \%$, no pump recycling) for the $900 \mathrm{~nm}$ and $906 \mathrm{~nm}$ emissions

\section{INTRACAVITY SECOND HARMONIC GENERATION}

The major aim of this work is to perform intracavity second harmonic generation to reach the blue range. Promising results have already been obtained by intracavity doubling of the Nd:ASL emission under Ti:Sa pumping at $792 \mathrm{~nm}$ : $225 \mathrm{~mW}$ of blue laser power at $450 \mathrm{~nm}$ under $3 \mathrm{~W}$ of incident pump power resulting in an optical-to-optical efficiency of $7.5 \%$, and a power as high as $320 \mathrm{~mW}$ with a $\mathrm{BiB}_{3} \mathrm{O}_{6}$ crystal in the same operating conditions [6]. Under diode pumping, second harmonic generation has then been achieved by inserting a $\mathrm{LiB}_{3} \mathrm{O}_{5}$ (LBO) crystal into our previous laser cavity (Fig. 12). The LBO crystal was $15-\mathrm{mm}$ long and cut for type-I phase-matching (see Table 2 for its main characteristics). We placed it as close as possible to the Nd:ASL crystal to maximize the intracavity laser intensity. In order to reduce the divergence of the laser beam and match the angular acceptance of the nonlinear crystal, the pump and laser waists have been increased to $20 \mu \mathrm{m}$. The temperature of the nonlinear crystal was controlled at $25^{\circ} \mathrm{C}$ by a Peltier module to adjust and stabilize the phase matching angle of the LBO. We obtained an output power of $53 \mathrm{~mW}$ at $453 \mathrm{~nm}$ for a maximum pump power of $1.5 \mathrm{~W}$ with the 3-mm long Nd:ASL crystal (see Fig. 11). Our results correspond to an optical-to-optical efficiency of $4 \%$. We are mainly limited by the accessible pump power which is limited to $1.5 \mathrm{~W}$. Moreover the results are limited by the degradation of the pump beam from the tapered amplifier at high operating current. The beam was close to the diffraction limit below $40 \mathrm{~mW}$ but degraded at maximum output powers with $\mathrm{M}^{2}$ values around 3 .

Table 2 LBO crystal characteristics

\begin{tabular}{|c|c|}
\hline length & $10 \mathrm{~mm}$ \\
\hline deff & $0.798 \mathrm{pm} . \mathrm{V}-1$ \\
\hline$(\boldsymbol{\theta}, \boldsymbol{\varphi})$ & $\left(90^{\circ}, 22.5^{\circ}\right)$ \\
\hline$\Delta \boldsymbol{\theta} . \mathbf{L} @ \mathbf{9 0 6} \mathbf{~ n m}$ & $4.41 \mathrm{mrad} . \mathrm{cm}$ \\
\hline
\end{tabular}

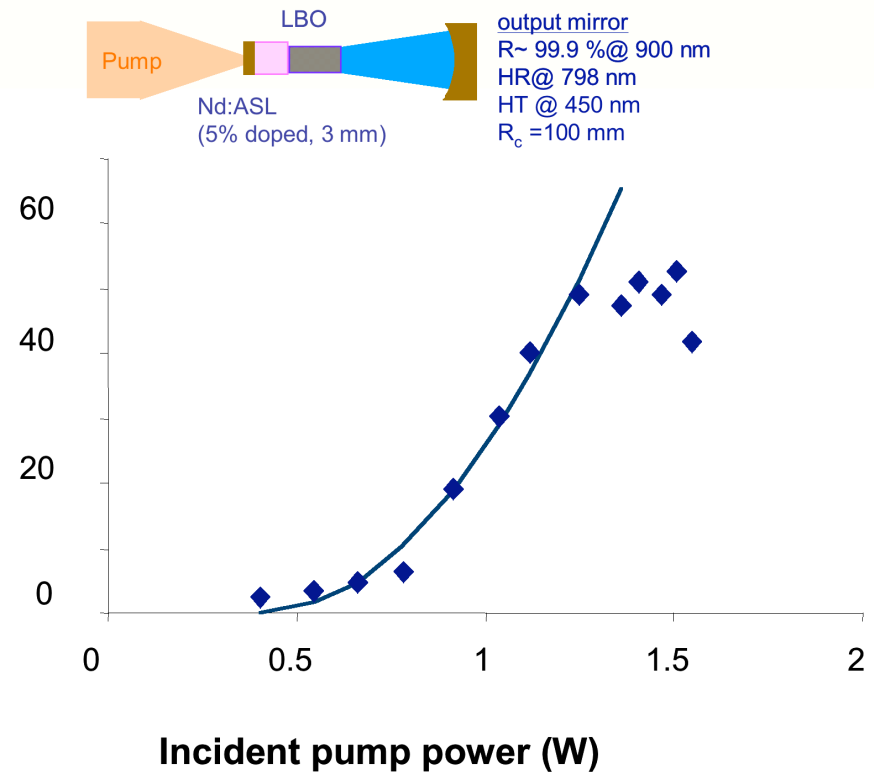


Fig. 11 SHG performance (dot - experimental values, line - parabolic fit) - Inset : experimental set-up for second harmonic generation

\section{CONCLUSION}

We have demonstrated the first diode pumping of a Nd:ASL crystal. We have developed our own high-brightness wavelength-stabilized pump source based on an extended cavity tapered amplifier with a volume Bragg grating suited to the optical pumping of this crystal (several watts, linewidth $<80 \mathrm{pm}$ ). It should be noted that the set-up we have used to lock our tapered amplifier in extended cavity can be adapted to other wavelengths with the appropriate volume Bragg grating provided that tapered amplifier structures exist at that wavelength.

A maximum output power of $126 \mathrm{~mW}$ at $900 \mathrm{~nm}$ has been obtained with a 3-mm long crystal. With a HR output coupler and with pump recycling, we obtained $300 \mathrm{~mW}$ at $906 \mathrm{~nm}$. Intracavity frequency doubling has also been performed with a LBO crystal to obtained $53 \mathrm{~mW}$ of blue laser at $453 \mathrm{~nm}$. This performance was limited by the beam quality of the pump source at high power. We believe that these results are an important step on the way to a compact and efficient design of a Nd:ASL blue emitting laser. Given the recent results in reliability and power (10W) of tapered laser [16,17], a higher pumping power can be expected which should lead to higher laser powers. Moreover, our results could be improved with a more efficient doubling crystal such as $\mathrm{BiBO}\left(\mathrm{BiB}_{3} \mathrm{O}_{6}\right)$.

\section{ACKNOWLEDGMENTS}

The authors thank Gilles Colas and Christian Beurthe for the polishing of the Nd:ASL crystals. This work has been partially supported by the European Community under the www.BRIGHT.eu integrated project (IP511722). D. Paboeuf acknowledges the funding of his PhD by the French Army (Délégation Générale de l'Armement).

\section{REFERENCES}

1 T. Y. Fan and R. L. Byer, "Modeling cw operation of a quasi-three-level 946 nm Nd:YAG laser", Opt. Lett. 12, 809 (1987)

2. P. Zeller and al., "Efficient, multiwatt, continuous-wave laser operation on the ${ }^{4} \mathrm{~F}_{3 / 2}-{ }^{4} \mathrm{I}_{9 / 2}$ transitions of $\mathrm{Nd}_{\text {: }} \mathrm{YVO}_{4}$ and Nd:YAG", Opt. Lett. 25, 34-36 (2000)

3 C. Czeranowsky and al., "Continuous wave diode pumped intracavity doubled Nd:GdVO 4 laser with $840 \mathrm{~mW}$ output power at 456 nm”, Opt. Commun. 205, 361-365 (2002)

M. Castaing, E. Hérault, F. Balembois, P. Georges, C. Varona, P. Loiseau, G. Aka, "Diode-pumped Nd:YAG laser emitting at $899 \mathrm{~nm}$ and below", Opt. Lett. 32, 799 (2007)

5 A. Lupei, V. Lupei, C. Gheorghe, D. Vivien, G. Aka, P. Aschehoug, "Spectroscopic and structural properties of Nd ${ }^{3+}$ doped strontium lanthanum aluminate laser crystals", J. Appl. Phys. 96, 3057 (2004)

6 C. Varona, P. Loiseau, G. Aka, B. Ferrand, V.Lupei, "CW blues laser emission by second harmonic generation of $900 \mathrm{~nm}$ oscillation of Nd-doped strontium and lanthanum aluminate (ASL)", Solid-State Lasers and Amplifiers, Proc. of SPIE, vol. 6190, pp. 27-32 (2006)

7 H. Wenzel, B. Sumpf, G. Erbert, « High-brightness diode lasers », C. R. Physique 4 (2003) 649-661

8 M. Kelemen, J. Weber, G. Kaufel, G. Bihlmann, R. Moritz, M. Mikulla, G. Weimann, “Tapered diode lasers at 976 nm with $8 \mathrm{~W}$ nearly diffraction limited output power", Electronics Letters 41(18) p 1011-13 (2005)

9 F. Dittmar, B. Sumpf, J. Fricke, G. Erbert and G. Tränkle, « High-Power 808-nm Tapered Diode Lasers With Nearly Diffraction-Limited Beam Quality of $\mathrm{M}^{2}=1.9$ at $\mathrm{P}=4.4 \mathrm{~W} »$, IEEE Photonics Technology Letters 18 (4) pp601603 (2006)

10 H. Kogelnik, Bell System Tech. Journ. 48, 2909-2945 (1969)

11 B. Fermigier, G. Lucas-Leclin, J. Dupont, F. Plumelle, M. Houssin "Self-aligned external-cavity semiconductor lasers for high resolution spectroscopy" Opt. Comm. 153 no.1-3, p.73-77 (1998)

12 P. Zorabedian and W. Trutna, "Interference-filter-tuned, alignement stabilized, semiconductor external-cavity laser", Optics Letters 13 (10), 826-828 (1988) 
13 S. Yiou, F. Balembois and P. Georges., "Numerical modeling of a continuous-wave Yb-doped bulk crystal laser emitting on a three-level laser transition near $980 \mathrm{~nm}$ ", J. Opt. Soc. Am. B 22, 572 (2005)

14 E. Hérault, F. Balembois and P. Georges, "Nd:GdVO 4 as three-level laser at 879 nm" Opt. Lett. 31, 2731 (2006)

15 S. Taccheo, P. Laporta and C. Svelto, "Widely tunable single-frequency erbium-ytterbium phosphate glass laser", Appl. Phys. Lett. 68, 2621 (1996)

16 F. Dittmar, B. Sumpf, G. Erbert and G. Tränkle, "Long-term reliability studies of high-power 808 nm tapered diode lasers with stable beam quality", Semicond. Sci. Technol. 22 (2007) 374-379

17 K. Paschke, S. Einfeldt, Ch. Fiebig, A. Ginolas, K. Häusler, P. Ressel, B. Sumpf, and G. Erbert, " 10W reliable operation of $808 \mathrm{~nm}$ broad-area diode lasers by near-field distribution control in a multistripe contact geometry", Proc. SPIE 6456, 64560H (2007) 